\title{
PENDAMPINGAN PENDIDIKAN ANAK USIA (PAUD) CAHAYA BUNDA DI JEMBATAN MERAH KOTA SURABAYA
}

\author{
Ratno Abidin, M.Pd ${ }^{1}$, Aristiana Prihatining Rahayu, S.Sos.,M.Met.,Kom ${ }^{2}$ \\ ${ }^{1}$ Fakultas Keguruan dan Ilmu Pendidikan, Universitas Muhammadiyah Surabaya \\ (penulis 1) email: abyratno@gmail.com \\ ${ }^{2}$ Fakultas Keguruan dan Ilmu Pendidikan, Universitas Muhammadiyah Surabaya \\ (penulis 2) email: aristianapr@yahoo.co.id
}

\begin{abstract}
ABSTRAK
Kegiatan pengabdian pada masyarakat di bantaran sungai jembatan merah Kelurahan Nyamplungan Kecamatan Pabean Cantika Kota Surabaya. Mereka bertempat tinggal dengan seadanya, bahkan bisa dibilang tempat tinggal mereka beratapkan langit beralaskan bumi, artinya mereka hanya tidur di emperan toko atau gudang yang seadanya yang sering di usir oleh SATPOL PP. Pekerjaan mereka memulung, meminta-minta dan ngamen di stopan lampu merah, toko-toko di pasar Kapasan Kota Surabaya. Selama ini mereka tidak diakui oleh pemerintah kota Surabaya karena tidak memiliki Kartu Tanda Penduduk dan Kartu Keluraga. Padahal merekan di Jempatan Merah Sudah bertahun-tahun bahkan sejak lahir. Melihat susahnya mereka untuk mendapatkan hak dan pengakuan dari Pemerintah Kota Surabaya dan mendapatkan kelayakan hidup. Tim bekerjasama dengan Pimpinan Cabang Muhammadiyah Kota Surabaya selama ini membantu warga yang tinggal di bantaran sungai Jembatan Merah. Program yang telah dilaksanaka Pengajian, Tempat Pendidikan Al quran, Pendidikan Anak Usia Dini, pembelajaran membaca, menulis dan membuat kerajinan.Permasalahan utamadalamPengentasan Anak Jalanan dan Gelandangan Buta Aksara Di Jembatan Merah Kelurahan Nyamplungan Kecamatan Pabean Cantika Kota Surabaya.
\end{abstract}

Kata Kuci: Pendampingan, PAUD Cahaya Bunda

\section{PENDAHULUAN}

\section{Analisis Situasi}

Perkembangan lembaga pendidikan prasekolah tengah mendapatkan perhatian serius dari pemerintahan, karena masa usia dini adalah masa yang sangat penting dalam sepanjang perjalan hidup manusia, pada masa ini merupakan masa pembentukan pondasi dan dasar kepribadian yang akan menentukan pengalaman anak selanjutnya, seperti dikemukakan oleh Hurlock (1991: 27) bahwa tahun-tahun awal kehidupan anak merupakan dasar yang cenderung bertahan dan mempengaruhi sikap dan prilaku anak sepanjang hidupnya. Masa ini anak memiliki karakteristik yang khas, baik secara fisik, psikis, moral dan sebagainya.

Pendidikan anak usia dini adalah upaya pembinaan yang ditunjukkan kepada anak sejak lahir sampai dengan usia 6 tahun yang dilakukan melalui pemberian rangsangan pendidikan untuk membantu pertumbuhan dan perkembangan jasmani dan rohani agar anak memiliki kesiapan dalam memasuki pendidikan lebih lanjut. Taman kanak-kanak adalah salah satu bentuk satuan pendidikan formal yang menyelenggarakan program pendidikan bagi anak usia 4-6 tahun.

Pendidikan ditaman kanak-kanak dilaksanakan dengan prinsip bermain sambil belajar, belajar seraya bermain sesuai dengan perkembangan anak didik. Usia 4-6 tahun merupakan masa peka bagi anak. Anak mulai sensitif untuk menerima berbagai upaya perkembangan seluruh potensi anak. Masa peka adalah masa terjadinya pematangan fungsi. Fungsi fisik dan psikis yang siap merespon stimulasi yang diberikan oleh lingkungan. Masa ini merupakan masa untuk meletakan dasar pertama dalam mengembangkan kemampuan fisik, kognitif, bahasa, sosial 
emosional, konsep diri, disiplin, kemandirian, seni, moral dan nilai-nilai agama. Oleh karena itu, dibutuhkan kondisi dan stimulasi yang sesuai dengan kebutuhan anak agar pertumbuhan dan perkembangan anak tercapai secara optimal.

Kecerdasan motorik anak berbeda-

beda, dalam hal kekuatan maupun ketetapannya perbedaan ini dipengaruhi oleh pembawaan anak dan stimulasi yang didapatkan. Lingkungan (orang tua) mempunyai pengaruh besar dalam kecerdasan motorik halus anak, lingkungan juga dapat meningkatkan/ menurunkan taraf kecerdasan anak terutama pada masa-masa pertama kehidupannya.

Kegiatan pembelajaran akan tercapai hasil yang optimal, apabila guru dapat memilih metode yang tepat, kemudian melaksanakannya dengan tehnik-tehnik penyampaian yang baik. Termasuk dalam pembelajaran pengembangan motori halus anak perlu disampaikan dengan tepat dan dilaksanakan dengan tehnik penyampaian yang baik.

Dengan sifat dasar alami setiap manusia, kita bisa melihat dengan nyata dimana anak-anak begitu sering asyik bermain-main dengan sesuatu benda atau melakukan sesuatu perbuatan yang dirinya sendiri belum mengetahui manfaat dan bahayanya. Kondisi ini merupakan indikasi objektif yang membenarkan bahwa setiap manusia bersifat dinamis dan memiliki rasa ingin tahu, misalnya tentang benda-benda tajam seperti pisau, silet, cutter, alat mencocok, gunting dan lain-lain.

Berdasarkan hasil observasi tim terdapat50 keluarga yang tinggal di bantaran sungai jembatan merah Kelurahan Nyamplungan Kecapatan Pabean Cantika Kota Surabaya. Mereka bertempat tinggal dengan seadanya, bahkan bisa dibilang tempat tinggal mereka beratapkan langit beralaskan bumi, artinya mereka hanya tidur di emperan toko atau gudang yang seadanya yang sering di usir oleh SATPOL PP.

Pekerjaan mereka dengan memulung, meminta-minta dan ngamen di stopan lampu merah dan toko-toko di pasar Kapasan Kota Surabaya. Selama ini mereka tidak diakui oleh pemerintah kota Surabaya karena tidak memiliki Kartu Tanda
Penduduk dan Kartu Keluraga.Padahal merekan di Jempatan Merah Sudah bertahun-tahun bahkan sejak lahir. Melihat susahnya mereka untuk mendapatkan hak dan pengakuan dari Pemerintah Kota Surabaya dan mendapatkan kelayakan hidup. Tim bekerjasama dengan Pimpinan Cabang Muhammadiyah Kota Surabaya selama ini membantu warga yang tinggal di bantaran sungai Jembatan Merah. Program yang telah dilaksanaka Pengajian, Tempat Pendidikan Al quran, Pendidikan Anak Usia Dini, pembelajaran membaca, menulis dan membuat kerajinan.

\section{Permasalahan Mitra}

Belum adanya gedung sekolah untuk melaksnakan pembelajara, sehingga pelaksanaan pembelajaran dilakukan di bantaran sungai jembatan merah.Kurangnya tenaga pendidik dalam mengajarkan terampilan pada anak usia dini. Kurangnya fasilitas pendidikan yang layak diberikan kepada siswa. Kurangnya kesadaran orang tua siswa untuk menyekolahkan anaknya, sehingga anak yang ada dibataran sungai jembatan merah lebih suka bekerja mengamen, mengemis dan meminta-minta di stopan lampu merah, toko dan tempat wisata Ampel surabaya.

Permaslahan lain adalah anak lebih suka bekerja daripada belajar adau sekolah. $\mathrm{Hal}$ ini perlu pendampingan atau sosialisasi ke orang tua siswa supaya anaknya diizinkan untuk sekolah. Dari tingkat pendidikan orang tuanya mereka rata-rata lulusan SD bahkan ada yang belum perna mengenyam bangku kuliah.

\section{Solusi yang Ditawarkan}

Dalam mengatasi permasalahan tersebut diperlukan penguatan kapasitas oleh pengurus PAUD Cahaya Bunda Jembatan Merah kota Surabaya.

Memberikan penyadaran ke orang tua siswa pentingnya anak usia dini mendapatkan pendidikan mulai usia dini, dengan cara mengundang warga yang tinggal di bantaran sungai jembatan merah untuk memikirkan anak-anaknya sekolah .Sarana dan prasarana merupakan 
perlengkapan dalam penyelenggaraan dan pengelolaan kegiatan pendidikan, pengasuhan, dan perlindungan anak usia dini. Pengadaan sarana dan prasarana perlu disesuaikan dengan jumlah anak, usia, lingkungan sosial dan budaya lokal, serta jenis layanan.

Prinsip pengadaan sarana prasarana meliputi:

a. aman, bersih, sehat, nyaman, dan indah;b.sesuai dengan tingkat perkembangan anak; c. memanfaatkan potensi dan sumberdaya yang ada di lingkungan sekitar, dan benda lainnya yang layak pakai serta tidak membahayakan kesehatan anak.Untuk sementara penyewaan gedung atau rumah yang bisa digunakan sebagai tempat pendidikan anak usia dini.

Guru berperan sebagai pengajar, dalam hal ini guru harus mengajar sesuai dengan kurikulum tanpa melihat minat anak. Semua anak dianggap botol kosong yang harus diisi oleh berbagai informasi tanpa melihat perbedaan bahkan meski anak tidak berminat pun guru harus tetap menyampaikan apa yang sudah dugariskan dalam kurikulum tersebut. Pada pendekatan ini guru berpegang pada panduan kemampuan yang akan dicapai anak dengan cara memahami minat, perasaan dan pengalaman anak.

Guru hanya berperan sebagai fasilitator dengan memberikan kesempatan kepada anak untuk mengungkapkan pengalaman, perasaannya melalui berbagai interaksi kepada guru maupun teman sebaya. Dalam hal ini anak dapat dengan leluasa mengekspresikan apa saja yanga ada dalam pikirannya Pendekatan semacam ini merupakan pendekatan yang efektif dan terbaik karena anak dapat berkembang secara utuh. Adanya penambahan guru atau mahasiswa magang 1 , magang 2 dan magang/PPL 3 dari mahasiswa Prodi PG PAUD FKIP UMSurabaya di PAUD Cahaya Bunda Jembatan Merah Kota Surabaya.

\section{METODE PELAKSANAAN}

\section{Waktu dan Tempat Kegiatan}

Kegiatan pengabdian dilaksanakan selama 6 bulan di PAUD Cahaya Bunda Jembatan Merah Kota Surabaya.

\section{Sasaran Pengabdian}

Sasaran dari kegiatan ini adalah anak-anak usia dini yang ada di bantaran sungai jembatan merah kota surabaya yang selama ini mereka belum mendapatkan pendidikan. PAUD Cahaya Bunda sebagai wadah untuk memberikan pendidikan yang layah bagi anak-anak usia dini. Tim pengabdian mencoba membuat model pembelajaran yang menarik untuk menarik minat dari orang tua sehingga anaknya bisa di sekolahkan. Selama PAUD Cahaya Bunda berdiri ada dua pendiri atau pengurus yang selama tim pengabdian turun kelapangan ikut mendampingi, yaitu bu Cica dan bu Aris. Kedua pengurus ini yang membantu anak-anak yang ada dijembatan merah.

\section{Metode yang Digunakan}

Dalam pengabdian ini tim menggunakan metode diskusi, ceramah dan tanyajawab. Diskusi dengan warga yang tinggal dibantaran sungai jembatan merah. Memberikan pandangan dan motivasi pentingnya anak usia dini mulai belajar. Memberikan contoh dalam mendidik anak tanpa menggunakan kekerasan. Adapun mengenai program kegiatannya adalah sebagai tabel berikut berikut :

\begin{tabular}{|c|c|c|c|c|}
\hline No & Program & $\begin{array}{c}\text { Jenis } \\
\text { Kegiatan }\end{array}$ & Target & Sasaran \\
\hline 1 & $\begin{array}{l}\text { Mengurus } \\
\text { Perijinan } \\
\text { PAUD } \\
\text { Mengurus } \\
\text { Identitas Diri } \\
\text { Anak ( akte } \\
\text { kelahiran) } \\
\text { Pembenahan } \\
\text { administrasi } \\
\text { paud }\end{array}$ & $\begin{array}{l}\text { - Mengurus } \\
\text { perijinan } \\
\text { terkait PAUD } \\
\text { yang terletak } \\
\text { dijalan } \\
\text { panggung. } \\
\text { mengurus } \\
\text { akta } \\
\text { kelahiran } \\
\text { anak yang } \\
\text { tinggal di } \\
\text { jalan } \\
\text { panggung ( } \\
\text { terutama } \\
\text { anak PAUD) } \\
\text { - } \\
\text { memperbaiki } \\
\text { administrasi } \\
\text { yag ada } \\
\text { didalam } \\
\text { PAUD } \\
\text { terdahulu }\end{array}$ & $\begin{array}{l}\text { Memoti } \\
\text { vasi } \\
\text { warga } \\
\text { untuk } \\
\text { lebih } \\
\text { memper } \\
\text { hatikan } \\
\text { tentang } \\
\text { pendidik } \\
\text { an anak } \\
\text { mereka }\end{array}$ & $\begin{array}{l}\text { Semua } \\
\text { Warga } \\
\text { jalan } \\
\text { panggung } \\
\text { kelurahan } \\
\text { Nyamplun } \\
\text { gan }\end{array}$ \\
\hline 2 & $\begin{array}{l}\text { Pembelajaran } \\
\text { Tema: Diri }\end{array}$ & $\begin{array}{l}\text { Memberikan } \\
\text { sosialisasi }\end{array}$ & $\begin{array}{l}\text { Memoti } \\
\text { vasi }\end{array}$ & $\begin{array}{l}\text { Semua } \\
\text { Warga }\end{array}$ \\
\hline
\end{tabular}




\begin{tabular}{|c|c|c|c|c|}
\hline & $\begin{array}{l}\text { Sendiri } \\
\text { SubTema: } \\
\text { Identitas }\end{array}$ & $\begin{array}{l}\text { mengenai } \\
\text { pentingnya } \\
\text { Identitas ( } \\
\text { akta } \\
\text { kelahiran ) } \\
\text { bagi anak } \\
\text { mereka. }\end{array}$ & $\begin{array}{l}\text { warga } \\
\text { untuk } \\
\text { melengk } \\
\text { api } \\
\text { identitas } \\
\text { mereka } \\
\text { dan } \\
\text { anak } \\
\text { mereka }\end{array}$ & $\begin{array}{l}\text { jalan } \\
\text { panggung } \\
\text { kelurahan } \\
\text { Nyamplun } \\
\text { gan }\end{array}$ \\
\hline 3 & $\begin{array}{l}\text { Workshop } \\
\text { menggambar }\end{array}$ & $\begin{array}{l}\text { Memberikan } \\
\text { kertas } \\
\text { bergambar } \\
\text { agar diwarnai } \\
\text { anak } \\
\text { Menunjukka } \\
\text { n beberapa } \\
\text { gambar yang } \\
\text { menarik }\end{array}$ & $\begin{array}{l}\text {.Memoti } \\
\text { vasi } \\
\text { anak } \\
\text { agar } \\
\text { mengepr } \\
\text { esikan } \\
\text { kreatifit } \\
\text { as } \\
\text { mereka } \\
\text { melalui } \\
\text { media } \\
\text { mengga } \\
\text { mbar }\end{array}$ & $\begin{array}{l}\text { Anak-anak } \\
\text { jalan } \\
\text { panggung } \\
\text { kelurahan } \\
\text { Nyamplun } \\
\text { gan }\end{array}$ \\
\hline 4 & $\begin{array}{l}\text { Pembelajaran } \\
\text { Tema: Diri } \\
\text { Sendiri } \\
\text { SubTema: } \\
\text { Kesukaan }\end{array}$ & $\begin{array}{l}\text { Menyebutkan } \\
\text { nama-nama } \\
\text { hari } \\
\text { Lempar } \\
\text { tangkap bola }\end{array}$ & $\begin{array}{l}\text { Anak } \\
\text { dapat } \\
\text { mengen } \\
\text { al nama } \\
\text { hari dan } \\
\text { bermain } \\
\text { lempar } \\
\text { angkap } \\
\text { bola }\end{array}$ & $\begin{array}{l}\text { Anak } \\
\text { PAUD }\end{array}$ \\
\hline 5 & $\begin{array}{l}\text { Pembelajaran } \\
\text { Tema: } \\
\text { Kebutuhan } \\
\text { SubTema: } \\
\text { Kebersihan, } \\
\text { Kesehatan, } \\
\text { Keamanan }\end{array}$ & $\begin{array}{l}\text { Cara memilih } \\
\text { makanan } \\
\text { yang sehat } \\
\text { Cara mencuci } \\
\text { tangan }\end{array}$ & $\begin{array}{l}\text { Member } \\
\text { ikan } \\
\text { pendidik } \\
\text { an } \\
\text { tentang } \\
\text { makana } \\
\text { n yang } \\
\text { bersih } \\
\text { dan cuci } \\
\text { tangan } \\
\text { yang } \\
\text { benar }\end{array}$ & $\begin{array}{l}\text { Anak } \\
\text { PAUD }\end{array}$ \\
\hline 6 & $\begin{array}{l}\text { Kampung } \\
\text { Dolanan }\end{array}$ & $\begin{array}{l}\text { Menemani } \\
\text { anak PAUD } \\
\text { bermain } \\
\text { dengan } \\
\text { menggunaka } \\
\mathrm{n} \text { alat } \\
\text { Permainan } \\
\text { Educativ }\end{array}$ & $\begin{array}{l}\text { Memoti } \\
\text { vasi } \\
\text { anak } \\
\text { PAUD } \\
\text { untuk } \\
\text { lebih } \\
\text { kreatif }\end{array}$ & $\begin{array}{l}\text { Anak } \\
\text { PAUD } \\
\text { jalan } \\
\text { panggung } \\
\text { Kelurahan } \\
\text { Nyamplun } \\
\text { gan }\end{array}$ \\
\hline 7 & $\begin{array}{l}\text { Penyuluhan } \\
\text { PHBS }\end{array}$ & $\begin{array}{l}\text { Memberikan } \\
\text { Sosialisasi } \\
\text { tentang } \\
\text { Hidup Bersih } \\
\text { dan Sehat } \\
\text { Sosialisasi } \\
\text { pentingnya } \\
\text { cuci tangan } \\
\text { Mendemonst } \\
\text { rasikan cara } \\
\text { cuci tangan } \\
\text { yang benar. }\end{array}$ & $\begin{array}{l}\text { Memoti } \\
\text { vasi } \\
\text { warga } \\
\text { untuk } \\
\text { menjaga } \\
\text { kebersih } \\
\text { an } \\
\text { terutama } \\
\text { pada } \\
\text { diri } \\
\text { sendiri }\end{array}$ & $\begin{array}{l}\text { Semua } \\
\text { Warga } \\
\text { jalan } \\
\text { panggung } \\
\text { kelurahan } \\
\text { Nyamplun } \\
\text { gan }\end{array}$ \\
\hline 8 & $\begin{array}{l}\text { Pembelajaran } \\
\text { Tema: } \\
\text { Lingkungan } \\
\text { SubTema: } \\
\text { Lingkungan } \\
\text { Keluarga Inti }\end{array}$ & $\begin{array}{l}\text { Mengenal } \\
\text { anggota } \\
\text { keluarga dan } \\
\text { perannya }\end{array}$ & $\begin{array}{l}\text { Anak } \\
\text { lebih } \\
\text { mengen } \\
\text { al } \\
\text { tentang } \\
\text { keluarga }\end{array}$ & $\begin{array}{l}\text { Anak } \\
\text { PAUD }\end{array}$ \\
\hline 9 & $\begin{array}{l}\text { Bagi-bagi } \\
\text { baju bekas } \\
\text { dan mainan } \\
\text { untuk anak }\end{array}$ & $\begin{array}{l}\text { Menyiapkan } \\
\text { baju bekas } \\
\text { yang sudah } \\
\text { terkumpul } \\
\text { Membagikan }\end{array}$ & $\begin{array}{l}\text { Member } \\
\text { ikan } \\
\text { bantuan } \\
\text { berupa } \\
\text { baju dan } \\
\text { mainan }\end{array}$ & $\begin{array}{l}\text { Semua } \\
\text { Warga } \\
\text { jalan } \\
\text { panggung } \\
\text { kelurahan } \\
\text { Nyamplun } \\
\text { gan }\end{array}$ \\
\hline
\end{tabular}

\begin{tabular}{|c|c|c|c|c|}
\hline & & $\begin{array}{l}\text { baju bekas } \\
\text { dan mainan } \\
\text { untuk anak }\end{array}$ & & \\
\hline 10 & $\begin{array}{l}\text { Pembelajaran } \\
\text { Tema: } \\
\text { Lingkungan } \\
\text { SubTema: } \\
\text { Lingkungan } \\
\text { Sekolah }\end{array}$ & $\begin{array}{l}\text { Mengenal } \\
\text { lingkungan } \\
\text { sekolah }\end{array}$ & $\begin{array}{l}\text { Memoti } \\
\text { vasi } \\
\text { anak } \\
\text { untuk } \\
\text { bersekol } \\
\text { ah }\end{array}$ & $\begin{array}{l}\text { Anak } \\
\text { PAUD }\end{array}$ \\
\hline 11 & $\begin{array}{l}\text { Peringatan } 17 \\
\text { Agustus } \\
\text { Lomba } \\
\text { menggambar, } \\
\text { lomba } \\
\text { menyocokka } \\
\text { n bentuk, } \\
\text { lomba } \\
\text { mewarnai }\end{array}$ & $\begin{array}{l}\text { Mengadakan } \\
\text { lomba-lomba } \\
\text { yang } \\
\text { educative } \\
\text { untuk Anak- } \\
\text { anak } \\
\text { Memberikan } \\
\text { hadiah }\end{array}$ & $\begin{array}{l}\text { Menum } \\
\text { buhkan } \\
\text { rasa } \\
\text { Nasiona } \\
\text { lisme }\end{array}$ & $\begin{array}{l}\text { Anak- } \\
\text { anak } \\
\text { PAUD di } \\
\text { jalan } \\
\text { panggung } \\
\text { Kelurahan } \\
\text { Nyamplun } \\
\text { gan }\end{array}$ \\
\hline 12 & $\begin{array}{l}\text { Pembelajaran } \\
\text { Tema: } \\
\text { Rekreasi } \\
\text { SubTema: } \\
\text { Kendaraan } \\
\text { Darat }\end{array}$ & $\begin{array}{l}\text { Menjelaskan } \\
\text { gambar- } \\
\text { gambar } \\
\text { kendaraan } \\
\text { kepada anak- } \\
\text { anak }\end{array}$ & $\begin{array}{l}\text { Anak } \\
\text { Mengen } \\
\text { al } \\
\text { berbagai } \\
\text { macam } \\
\text { kendara } \\
\text { an }\end{array}$ & $\begin{array}{l}\text { Anak } \\
\text { PAUD }\end{array}$ \\
\hline 13 & $\begin{array}{l}\text { Pembagian } \\
\text { Makanan } \\
\text { Tambahan }\end{array}$ & $\begin{array}{l}\text { Membagikan } \\
\text { makanan } \\
\text { tambahan } \\
\text { kepada warga } \\
\text { jalan } \\
\text { panggung } \\
\text { kelurahan } \\
\text { Nyamplunga } \\
\text { n }\end{array}$ & 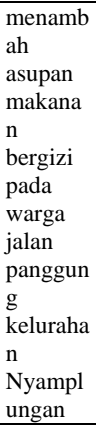 & $\begin{array}{l}\text { Semua } \\
\text { warga } \\
\text { jalan } \\
\text { panggung } \\
\text { kelurahan } \\
\text { Nyamplun } \\
\text { gan }\end{array}$ \\
\hline 14 & $\begin{array}{l}\text { Pembelajaran } \\
\text { Tema: } \\
\text { Rekreasi } \\
\text { SubTema: } \\
\text { Perkotaan }\end{array}$ & $\begin{array}{l}\text { Mempelajari } \\
\text { tentang } \\
\text { lingkungan } \\
\text { kota }\end{array}$ & $\begin{array}{l}\text { Anak } \\
\text { dapat } \\
\text { belajar } \\
\text { tentang } \\
\text { lingkun } \\
\text { gan kota }\end{array}$ & $\begin{array}{l}\text { Anak } \\
\text { PAUD }\end{array}$ \\
\hline 15 & $\begin{array}{l}\text { Pengumpulan } \\
\text { Identitas Diri } \\
\text { Anak yang } \\
\text { sudah } \\
\text { Diproses }\end{array}$ & $\begin{array}{l}\text { Mendokume } \\
\text { ntasikan } \\
\text { Identitas Diri } \\
\text { anak }\end{array}$ & $\begin{array}{l}\text { Hasil } \\
\text { dari } \\
\text { penguru } \\
\text { san } \\
\text { Identitas }\end{array}$ & $\begin{array}{l}\text { Anak } \\
\text { jalanan } \\
\text { jalan } \\
\text { Panggung } \\
\text { (terutama } \\
\text { anak } \\
\text { PAUD) }\end{array}$ \\
\hline 16 & $\begin{array}{l}\text { Kewirausaha } \\
\text { an : } \\
\text { Membuat } \\
\text { kerajinan } \\
\text { tangan dari } \\
\text { kaos kaki }\end{array}$ & $\begin{array}{l}\text { Pembelajaran } \\
\text { Ibu-ibu untuk } \\
\text { Membuat } \\
\text { kerajinan } \\
\text { tangan dari } \\
\text { kaos kaki }\end{array}$ & $\begin{array}{l}\text { Memba } \\
\text { ntu } \\
\text { perekon } \\
\text { omian } \\
\text { warga }\end{array}$ & $\begin{array}{l}\text { Ibu-ibu } \\
\text { jalan } \\
\text { Panggung } \\
\text { kelurahan } \\
\text { Nyamplun } \\
\text { gan } \\
\end{array}$ \\
\hline 17 & $\begin{array}{l}\text { Pembelajran } \\
\text { SD Calistung } \\
\text {, Persiapan } \\
\text { Penutupan }\end{array}$ & $\begin{array}{l}\text { Mengajarkan } \\
\text { pada anak } \\
\text { cara } \\
\text { membaca } \\
\text { menulis dan } \\
\text { berhitung }\end{array}$ & $\begin{array}{l}\text { anak } \\
\text { dapat } \\
\text { belajar } \\
\text { tentang } \\
\text { Calistun } \\
\mathrm{g}\end{array}$ & $\begin{array}{l}\text { Anak } \\
\text { jalanan } \\
\text { jalan } \\
\text { Panggung } \\
\text { yang sudah } \\
\text { memasuki } \\
\text { anak usia } \\
\text { SD } \\
\end{array}$ \\
\hline 18 & Penutupan & $\begin{array}{l}\text { Pameran } \\
\text { (kreasi ibu } \\
\text { dan anak) } \\
\text { Serah terima } \\
\text { ID yang } \\
\text { sudahjadi } \\
\text { PENSI ( }\end{array}$ & $\begin{array}{l}\text { Memam } \\
\text { erkan } \\
\text { Hasil } \\
\text { karya } \\
\text { ibu dan } \\
\text { anak, } \\
\text { penyera } \\
\text { han ID } \\
\text { pada } \\
\text { ibu/anak }\end{array}$ & $\begin{array}{l}\text { Semua } \\
\text { Warga } \\
\text { jalan } \\
\text { panggung } \\
\text { kelurahan } \\
\text { Nyamplun } \\
\text { gan } \\
\text { (Terutama } \\
\text { anak } \\
\text { PAUD) }\end{array}$ \\
\hline
\end{tabular}




\begin{tabular}{|l|l|l|l|l|}
\hline & $\begin{array}{l}\text { menari, } \\
\text { fashion } \\
\text { show, } \\
\text { puisi/sair dll) }\end{array}$ & & & \\
& & & \\
\hline
\end{tabular}

\section{HASIL DAN PEMBAHASAN}

Mengurus Identitas Diri Anak ( akte kelahiran)Dengan adanya pegurusan identitas ini dapat membantu mereka untuk daftar masuk ke sekolah,tetapi data orang tua mereka ada yang tidak lengkap jadi harus diurus terlebih dahulu, pegurusan identitas pastinya memutuhkan waktu yang tidak sebentar, karna ada data yang harus diurus di luar kota yaitu kota kediri dan madura.

Warga dan Bunda PAUD ikut berpartisipasi menjadikan PAUD lebih bersih dan rapi, lebih bayak poster untuk pembelajaran PAUD. Kegiatan ini kurang maksimal karna tempat belajar yang berstatus pinjaman dan belum memiliki ijin resmi PAUD. Warga dan Bunda PAUD ikut berpartisipasi menjadikan PAUD lebih bersih dan rapi, lebih bayak poster untuk pembelajaran PAUD. Kegiatan ini kurang maksimal karna tempat belajar yang berstatus pinjaman dan belum memiliki ijin resmi PAUD. Ibu-ibu dapat membuat kerajinan tangan kokoru dan boneka kaos kaki yang mana bisa dijual untuk membantu perekonomian mereka. Mereka juga antusias terhadap kegiatan ini. Tapi tetap saja masalah utama mereka adalah modalnya.

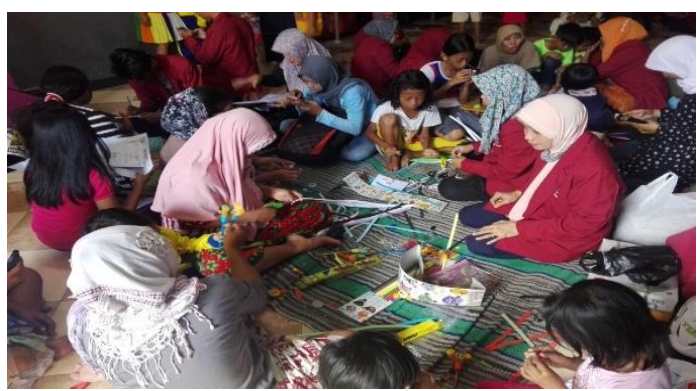

Gambar 1. Tim pengabdian dari PG PAUD FKIP UMSurabaya sosialisasi Pengurusan Identitas

Diri warga

Ibu-ibu mendapat pengetahuan tentang pentingnya persalinan di pelayanan kesehatan karena beberapa dari mereka melahirkan tidak di pelayanan kesehatan ataupun klinik resmi sehingga anak-anak yang mereka lahirkan datanya tidak tercatat secara resmi oleh Negara. Masalahnya tidak lain adalah ekonomi mereka yang tidak mencukupi. Mereka juga dapat memperaktekkan cara pemeriksaan payudara sendiri.Ibu-ibu belajar cara membuat pentol,peralatan masak untungnya tersedia ditempat tersebut jadi kami hanya menyiapkan bahan-bahannya saja.

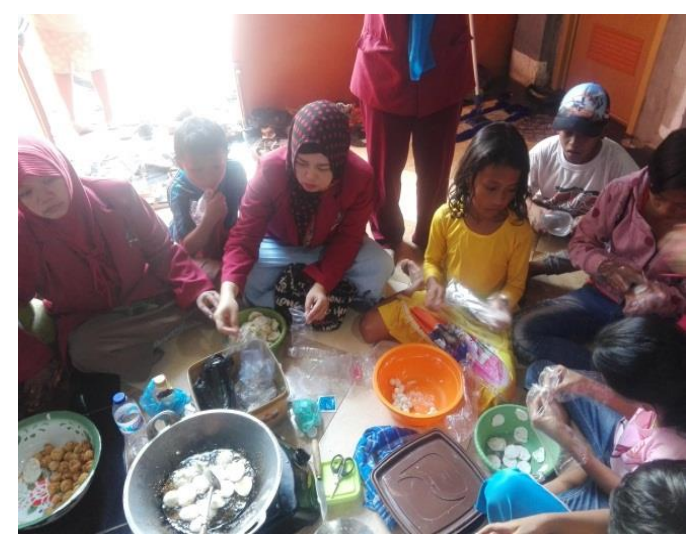

Gambar2.Parenting (Membuat cireng dan Onde-onde)

Pemberian makanan tambahan berupa kacang hijau yang sudah disiapkan para peserta untuk diberikan kepada anakanak. Tapi karna jumlah anak- anak yang datang tidak menentu dan keterbatasan biaya tidak bisa menyediakan stok yang banyak.

Mengajak anak-anak SD untuk menal lingkungan dengan bertamasya ke taman JMP, tidak mudah untuk mengatur anak-anak tersebut. Tetapi tenaga tim belum mumpuni untuk mengawal anak-anak tersebut dan mereka pun sangat bersemangat untuk belajar dan bermain di luar ruangan.

Dekorasi ruangan tidak bisa maksimal karena tidak boleh terlalu banyak menggunakan paku sehingga menghias semaksimal mungkin, acara dapat berjalan lancar. Anak-anak mengikuti lomba dengan semangat diiringi dengan lagu kemerdekaan.

Anak-anak dan ibu-ibu antusias mengikuti simulasi tersebut. Kami juga hanya bisa menguji sampel yang ada karena sulitnya menemukan makanan yang tidak memakai boraks. 


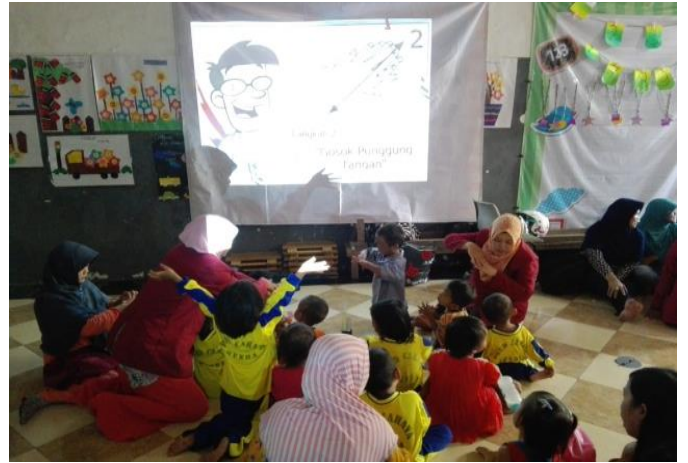

Gambar3.PHBS (Persalinan,Pemeriksaan Payudara Sendiri dan Gosok Gigi \& Cuci Tangan)

Anak-anak yang belum mendapat vitamin A karena datanya tidak tercantum di Posyandu, maka kami berinisiatif mengadakan posyandu di tempat PAUD dan menyiapkan sendiri Vitamin A dan alat-alat untuk mengukur tinggi dan berat badan.Pembagian baju yang sudah lama tapi masih layak pakai bagi warga yang kurang mampu.. Kami membagikannya perKepala Keluarga untuk mencegah terjadinya hal-hal yang tidak diinginkan. Dan membutuhkan tenaga yang ekstra karna jumlah pakaian dan keluarga yang banyak

Acara berjalan dengan lancer, kesulitannya hanya pada saat melatih mereka dan menentukan anak-anak mana yang akan tampil untuk pentas seni. Pada saat acara pentas seni dimulai juga susah mengatur anak-anak yang tidak tampil agar tidak naik kepanggung terutama anak PAUD.

\section{KESIMPULAN}

Pengabdian masyarakat adalah suatu gerakan proses pemberdayaan diri untuk kepentingan masyarakat yang mapu mendorong PAUD Cahaya Bunda Jembatan Merah kota Surabaya semakin eksis dalam membina dan mendidikan anak usia dini yang kurang beruntung.

\section{DAFTAR PUSTAKA}

Direktorat Pembinaan Taman Kanak-Kanak Dan Sekolah Dasar, (2007). Pedoman Pembelajaran Bidang Pengembangan Seni Di Taman Kanak-Kanak. Jakarta: Depdiknas
Elizabeth B. Hurlock. (2000). Psikologi Perkembangan: Suatu Pendekatan Sepanjang Rentang Kehidupan. Alih Bahasa Istiwidayanti. Jakarta; Erlangga.

Madiarti, Eris (2013), Peningkatkan Kemampuan Motorik Halus Anak Melalui Kegiatan Kolase Dengan Menggunakan Media Berbantuan Bahan Alam di Paud Melati Kabupaten Lebong. Skripsi. Pendidikan Bagi Guru Dalam Jabatan Pada Program Studi Pendidikan Anak Usia Dini Fakultas Keguruan dan Ilmu Pendidikan Universitas Riau, Tidak dipublikasikan. 